\title{
19. SONIC VELOCITY AND ELECTRICAL RESISTIVITY OF ROCK SAMPLES FROM HOLE 504B, LEG 83: MEASUREMENTS UNDER IN SITU CONDITIONS1
}

\author{
Hajimu Kinoshita, Department of Earth Sciences, Chiba University ${ }^{2}$
}

\begin{abstract}
Ultrasonic compressional and shear wave velocities of homogeneous basalt samples from the Leg 83 section of Hole 504B were measured under atmospheric and in situ conditions. In situ temperature and hydrostatic pressure were estimated based on temperature profiles (Becker et al., this volume) and on the densities of the basalt samples. In going from atmospheric to in situ conditions, compressional wave velocities increased by about $10 \%$, whereas shear wave velocities decreased by about $10 \%$. Electrical resistivities of dry basalt samples showed a drastic decrease in going from atmospheric to in situ temperature and pressure.
\end{abstract}

\section{INTRODUCTION}

A study was made of the variation with pressure (P) and temperature $(\mathrm{T})$ of compressional and shear wave velocities and electrical resistivities of selected, homogeneous basalt samples from the Leg 83 section of Hole 504B (836-1350 m sub-bottom). Measurements were made under conditions ranging from atmospheric to estimated in situ temperatures and pressures (Table 1).

The in situ temperature at the depth from which a given sample was cored was estimated by applying the conductive temperature profiles of Becker et al. (this volume). These indicate that temperatures could be closely approximated with linear gradients within each of three sections, each with a different thermal conductivity: the sediments (0-274.5 m), basement shallower than $836 \mathrm{~m}$, and basement deeper than $836 \mathrm{~m}$. Pressure at a given depth was assumed to be hydrostatic and was obtained by integrating the mass in a vertical column above the depth concerned. From the agreement of logging results (Anderson et al., 1982) and measurements of densities of samples at atmospheric conditions, it was assumed that densities could be approximated by two layers of constant value (Table 1): sediments $\left(2.5 \mathrm{~g} / \mathrm{cm}^{3}\right)$ and basement $\left(3.0 \mathrm{~g} / \mathrm{cm}^{3}\right)$. Figure 1 shows diagrams used to determine pressure-temperature values for the present studies.

\section{METHODS}

Samples for sonic velocity measurements were cut in cylinders $\sim 20$ $\mathrm{mm}$ long and $10 \mathrm{~mm}$ in diameter, moistened with seawater in a pressurizing vessel ( 5 bars) and sealed with copper plate $(100 \mu \mathrm{m}$ thick). Samples for electrical resistivity measurements were also cut in cylindrical shape, dried in hot air $\left(\sim 100^{\circ} \mathrm{C}\right)$, sealed in a teflon insulator tube, and again sealed with the copper plate. Ultrasonic waves were generated through lithium niobate single crystals with a high-speed and high-tension electric pulse (pulse width $=1 \mu \mathrm{s}$ and pulse height $=250$ V). Velocities were measured by a transmission method (i.e., delay time method). In addition to the pressure and temperature dependence

\footnotetext{
${ }^{1}$ Anderson, R. N., Honnorez, J., Becker, K., et al., Init. Repts. DSDP, 83: Washington (U.S., Govt. Printing Office).

Address: Dept. of Earth Sciences, Faculty of Sciences, Chiba University, Yayoi-cho, Chiba 260 Japan.
}

Table 1 . Temperature and density parameters used to determine pressure-temperature conditions.

\begin{tabular}{cccc}
\hline $\begin{array}{c}\text { Sub-bottom } \\
\text { depth }(\mathrm{m})\end{array}$ & $\begin{array}{c}\text { Depth from } \\
\text { sea level } \\
(\mathrm{m})\end{array}$ & $\begin{array}{c}\text { Temperature } \\
\left({ }^{\circ} \mathrm{C}\right)\end{array}$ & $\begin{array}{c}\text { Density } \\
\left(\mathrm{g} / \mathrm{cm}^{3}\right)\end{array}$ \\
\hline Mudline & 3460 & 20 & 1.025 \\
275 & 3735 & 60 & 2.50 \\
836 & 4296 & 120 & 3.00 \\
1350 & 4810 & 165 & 3.00 \\
\hline
\end{tabular}

of the sonic and electrical characteristics of solid samples, some frequency dependence of the electrical resistivity was measured. After several runs under various P-T conditions (up to 1000 bar and $220^{\circ} \mathrm{C}$ ), the electrical potential of $10 \mathrm{~Hz}$ (15 peak-to-peak volts) was selected and used in these studies. Pressure and temperature were regulated by an oil-powered hand pump with a high-precision pressure gauge and an inner heating system, driven by an ordinary electric power supply. Temperatures were measured by a thermistor attached to the surface of the specimen; calibration runs were made by comparing the temperature in the center of the specimen and on its surface prior to the experiments. Figure 2 shows a lateral view of the P-T vessels used for the present study.

\section{RESULTS}

\section{Sonic Velocities}

Shipboard measurements of compressional sonic velocities of homogeneous basalt samples from Hole 504B were made during Legs 69, 70 (Karato et al., 1983), and 83. We used a Hamilton Frame device, with a wave packet with a $500 \mathrm{kHz}$ main frequency. Figure 3 shows $100-$ $\mathrm{m}$ means and standard deviations of the results of these measurements. This velocity variation correlates well with the sonic-logging velocity value (Anderson et al., 1982). If a rebound of the elastic rock samples is to be taken in account, then the in situ velocities are probably several percentage points higher than the laboratory values.

In this study, the pressure and temperature dependence of compressional $\left(V_{\mathrm{p}}\right)$ and shear $\left(V_{\mathrm{s}}\right)$ sonic velocities were measured for five selected samples. Typical homogeneous basalt samples were picked from several depth 


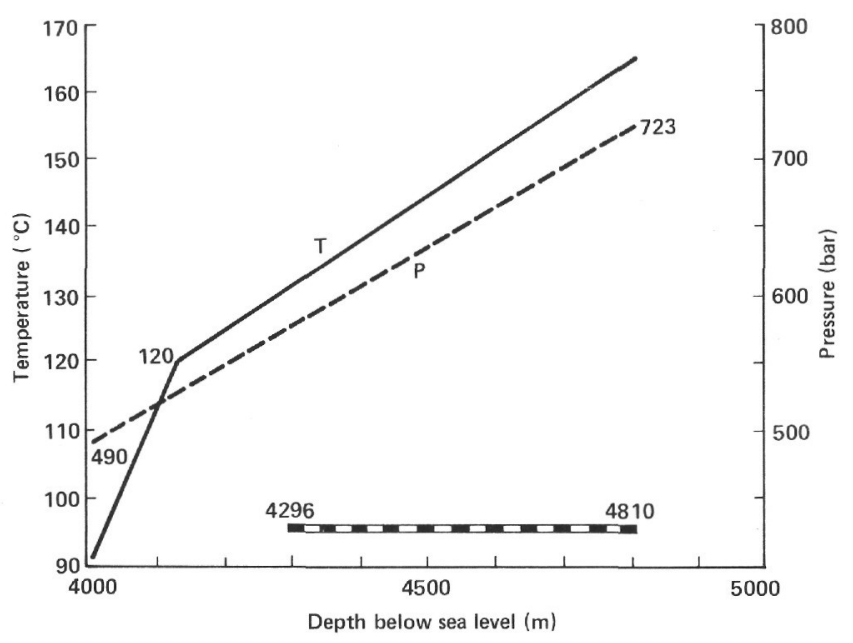

Figure 1. Reconstruction of approximate in situ pressure-temperature (P-T) conditions in Hole 504B based on logging temperature and on-board density measurements from Leg 83 . Horizontal bar represents the interval of Hole 504B drilled during Leg 83.

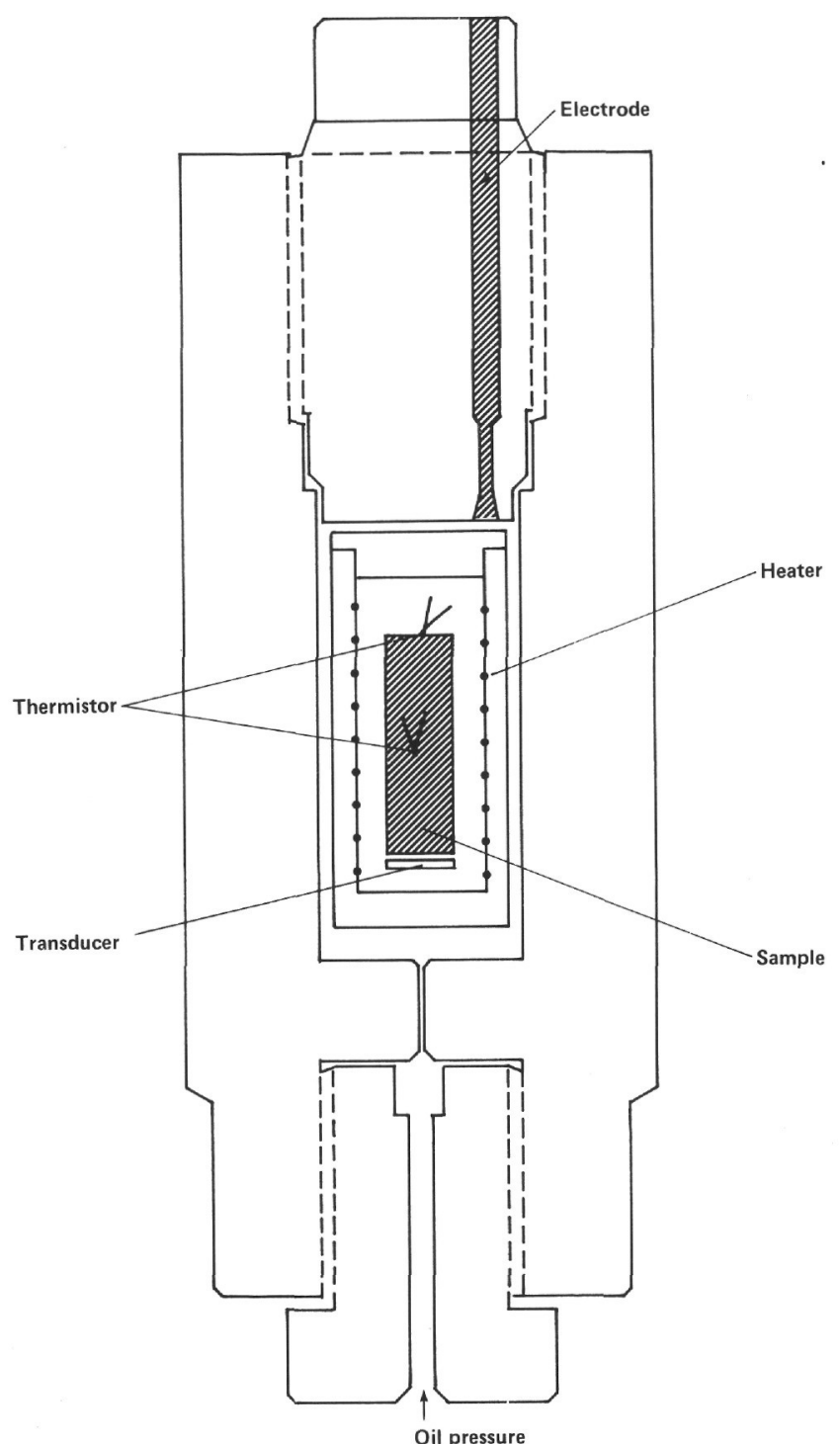

Figure 2. A lateral view of the pressure and temperature vessel.

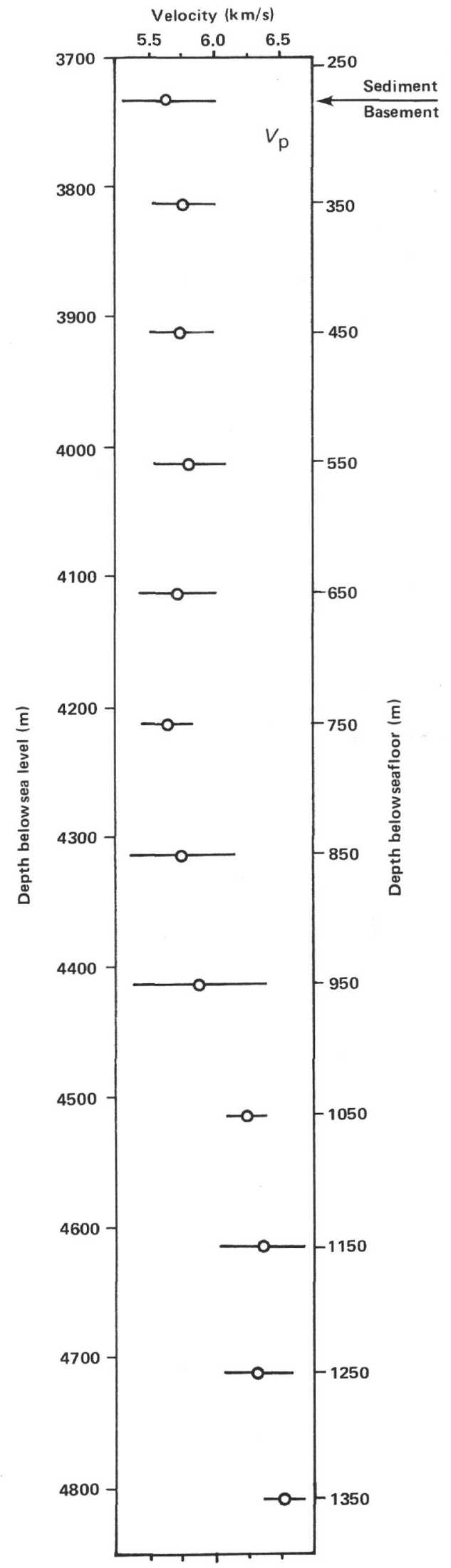

Figure 3. $V_{\mathrm{p}}$ of individual minicores recovered by Leg 83 , measured using the Hamilton Frame aboard Glomar Challenger. Running means of every $50 \mathrm{~m}$ sub-bottom are shown. 
intervals within the basement section cored by Leg 83 $(836-1350 \mathrm{~m}) . V_{\mathrm{p}}$ and $V_{\mathrm{s}}$ measurements were performed separately, and the velocity values were calculated under the assumption that the sample dimensions did not change in the complete range of experimental pressure and temperatures. From the pairs of $V_{\mathrm{p}}$ and $V_{\mathrm{s}}$ values, it was possible to calculate the variation with pressure and temperature of two elastic parameters, Poisson's ratio $(\sigma)$, and incompressibility $(K)$. This required the assumptions that the samples were isotropic and that pressure and temperature were precisely controlled. The results are illustrated in Figure 4.

For the rest of the samples, $V_{\mathrm{p}}$ and $V_{\mathrm{s}}$ were measured at both atmospheric and estimated in situ temperature and pressure. The procedure followed in attaining in situ conditions was, first, to pressurize hydrostatically to in situ pressure and then heat to in situ temperature, adjusting the pressure to maintain constant in situ value. It was assumed that the order of this operation did not affect the estimated in situ $V_{\mathrm{p}}$ and $V_{\mathrm{s}}$ values. The results are shown in Figure 10, later, where the $V_{\mathrm{p}}$ and $V_{\mathrm{s}}$ values under atmospheric conditions (open circles) and in situ $\mathrm{P}-\mathrm{T}$ conditions (solid circles) are connected by a straight line to show that they were obtained through single measurement runs. It is clear from both Figures 4 and 10, later, that the $V_{\mathrm{p}}$ and $V_{\mathrm{s}}$ obtained in situ differ significantly from those obtained in the open air. $V_{\mathrm{p}}$ values are rather influenced by the initial pressurization and less sensitive to the temperature change whereas $V_{\mathrm{s}}$ values are less sensitive to pressure but change considerably with heat.

\section{Electrical Resistivity}

Samples for electrical resistivity $(R)$ measurements were dried in order to avoid the ambiguity induced by surface, interstitial, and pore water, which may influence an electrical resistivity as the microstructure of rocks is deformed under P-T conditions. Actually, when a rock sample is moistened with normal seawater, the order of magnitude of the resistivity changes. Moreover, the frequency characteristics of the seawater resistivity and hard rock samples differ completely from each other, as illustrated in Figure 5. Direct-current (zero frequency) measurements under laboratory conditions could not be achieved because of a time-dependent (usually rapidly increasing) resistivity, probably resulting from an accumulation of carriers and holes adjacent to the electrodes attached to both ends of a small sample. After resistivity versus frequency characteristics of selected samples were measured under various $\mathrm{P}-\mathrm{T}$ conditions, an optimum frequency was fixed at $10 \mathrm{~Hz}$ for further measurements under in situ conditions.
The P-T and frequency and temperature dependencies of total resistance of some selected samples are illustrated in Figures 6 to 9. Sample resistivities under in situ conditions are shown in Figure 10 along with the sonic velocity values. Open and solid circles indicate $R$ values under open-air and in situ $\mathrm{P}-\mathrm{T}$ conditions, respectively.

\section{CONCLUSIONS}

These experimental studies indicate that

1. $V_{\mathrm{p}}$ of samples under in situ conditions is rather sensitive to pressure and is about $10 \%$ higher than $V_{\mathrm{p}}$ under atmospheric conditions.

2. $V_{\mathrm{s}}$ under in situ conditions is rather sensitive to temperature, and is about $10 \%$ lower than $V_{\mathrm{s}}$ under atmospheric conditions.

3. The resistivity of dry samples decreases by up to an order of magnitude in going from atmospheric to in situ conditions.

4. The resistivities of the samples as well as their variation with temperature and pressure show a dependence on the depths from which the samples were cored.

5. Near in situ conditions, the effect of temperature on $V_{\mathrm{p}}, V_{\mathrm{s}}$, and $R$ is greater than the effect of pressure.

The data presented here do not resolve the extent to which the variations in measured physical properties may be due to variations with depth of the hydrothermal alteration regime at Hole 504B. It is not clear how the measurements of resistivities of dry samples relate to the in situ resistivities of seawater-saturated crust. Karato (1983) measured resistivities of saturated samples from Hole 504B at atmospheric conditions. Further measurements under various $\mathrm{P}-\mathrm{T}$ conditions, including studies of thermal conductivities at in situ conditions, are presently being performed by the author, using a heat pulse method.

\section{REFERENCES}

Anderson, R. N., Honnorez, J., Becker, K., Adamson, A. C., Alt, J. C., Emmermann, R., Kempton, P. D., Kinoshita, H., Laverne, C., Mottl, M., and Newmark, R. L., 1982. DSDP Hole 504B, the first reference section over $1 \mathrm{~km}$ through Layer 2 of the oceanic crust. Nature, 300:589-594.

Karato, S., 1983. Physical properties of basalts from Deep Sea Drilling Project Hole 504B, Costa Rica Rift. In Cann, J. R., Langseth, M. G., Honnorez, J., Von Herzen, R. P., White, S. M., et al., Init. Repts. DSDP, 69: Washington (U.S. Govt. Printing Office), 687-695.

Karato, S., Wilkens, R. H., and Langseth, M. G., 1983. Shipboard physical-properties measurements of basalts from the Costa Rica Rift, Deep Sea Drilling Project Legs 69 and 70. In Cann, J. R., Langseth, M. G., Honnorez, J., Von Herzen, R. P., White, S. M., et al., Init. Repts. DSDP, 69: Washington (U.S. Govt. Printing Office), 675-681.

Date of Acceptance: 15 December 1983 

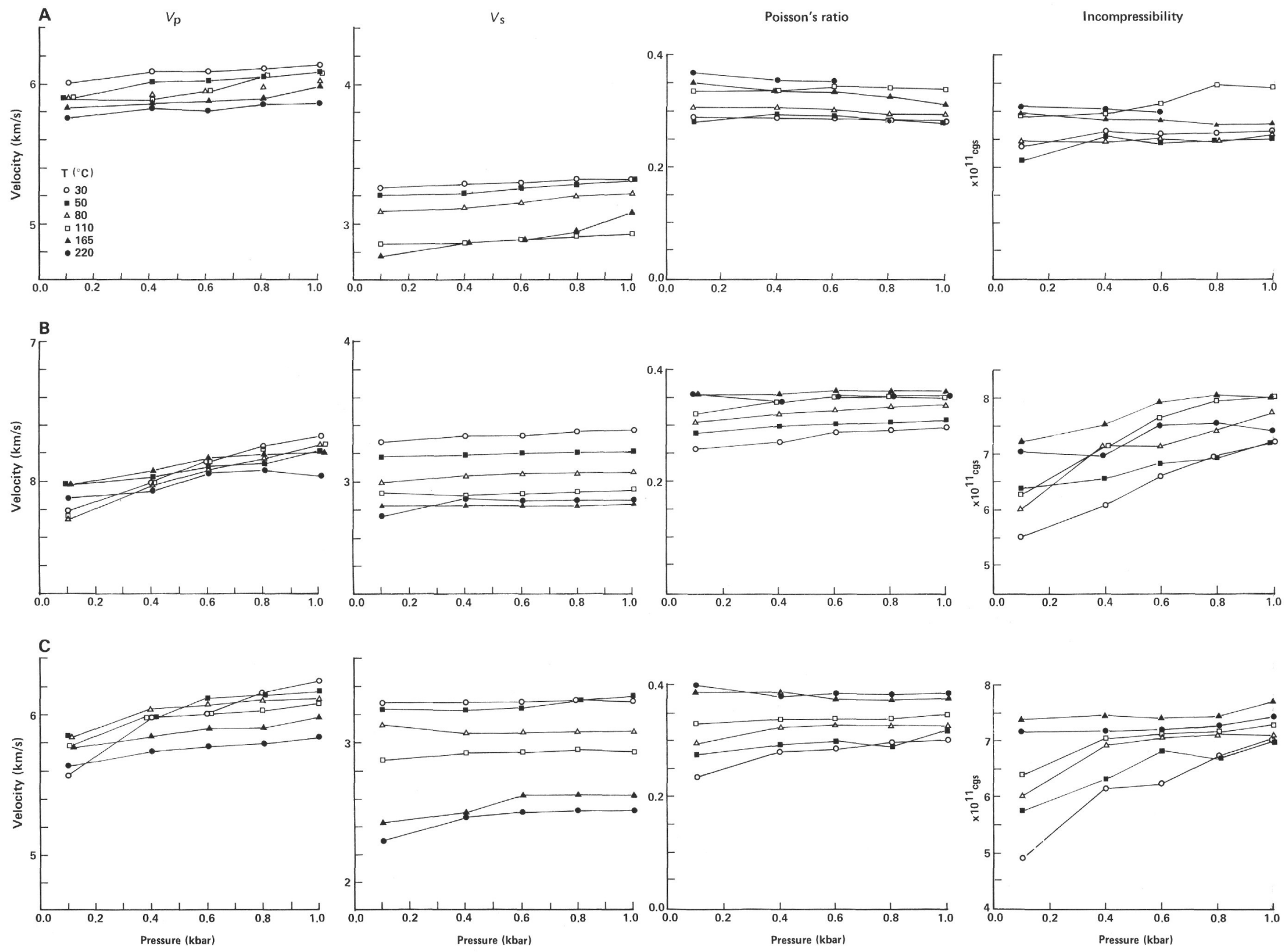

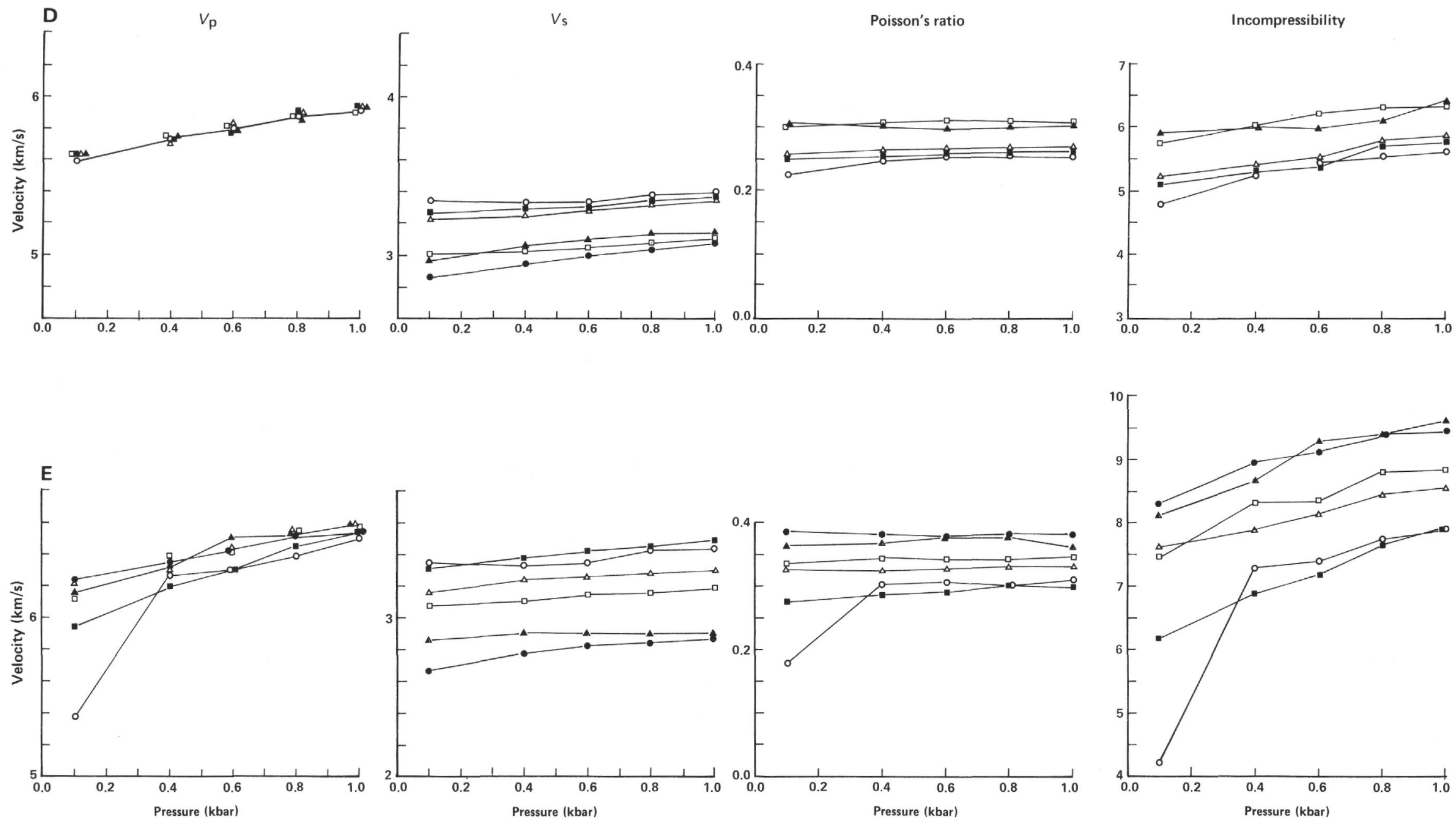

Figure 4. $V_{\mathrm{p}}$ and $V_{\mathrm{s}}$ under different pressures and temperatures, Hole 504B. Poisson's ratio and incompressibility are derived from a pair of $V_{\mathrm{p}}$ and $V_{\mathrm{s}}$ values. A. Section 72-2. B. Section 73-1. C. Section 87.2. D. Section 100-1. E. Section 133-2. 


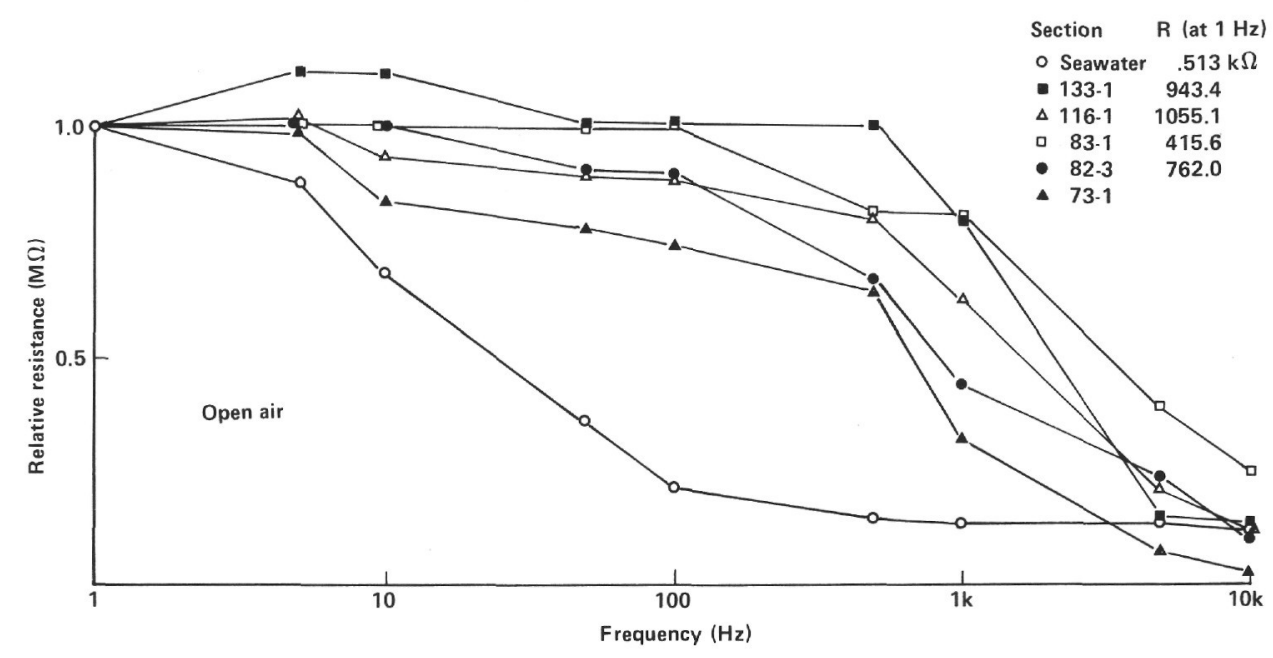

Figure 5. Frequency dependence of arbitrary resistivities of hard-rock samples from Hole 504B, measured at atmospheric pressure and room temperature.
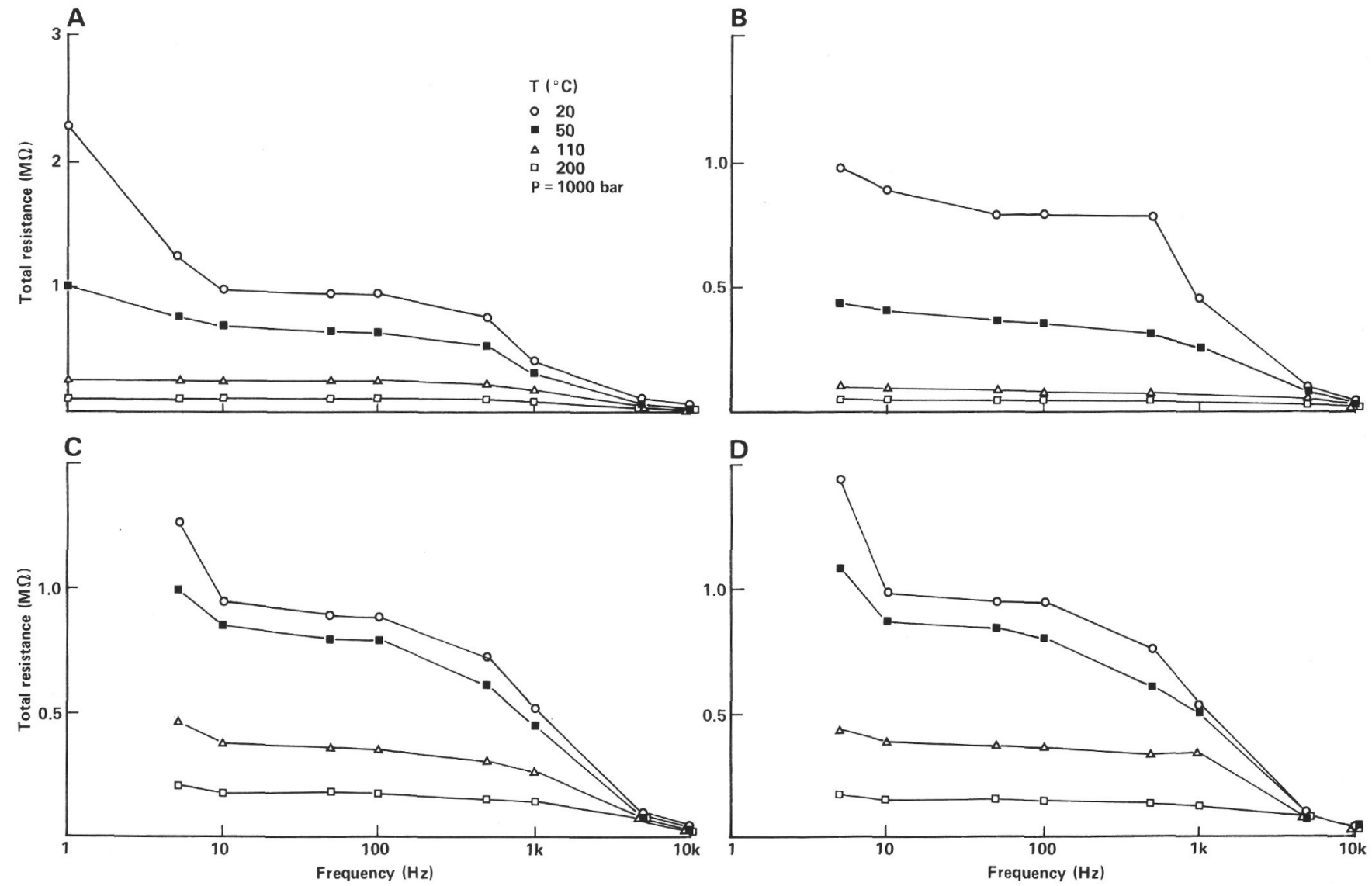

Figure 6. Frequency dependence of total resistivity of hard-rock samples from Hole 504B at different temperatures, under pressure of $1 \mathrm{kbar}$. A. Section 73-1. B. Section 83-1. C. Section 116-1. D. Section 136-1. 


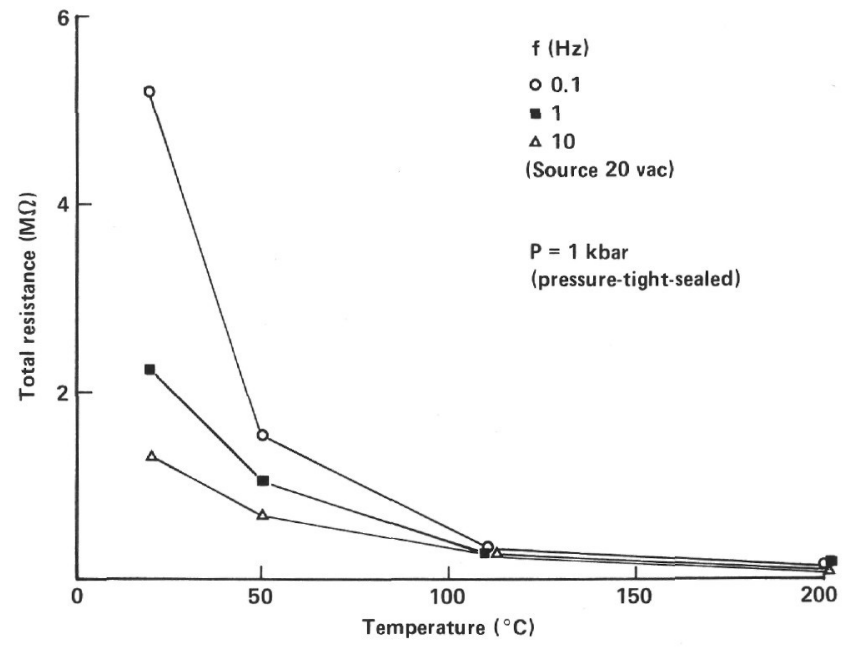

Figure 7. Change in total resistivity with respect to temperature in Hole 504B, measured under a pressure of 1 kbar with different source frequencies (f). Section 73-1.
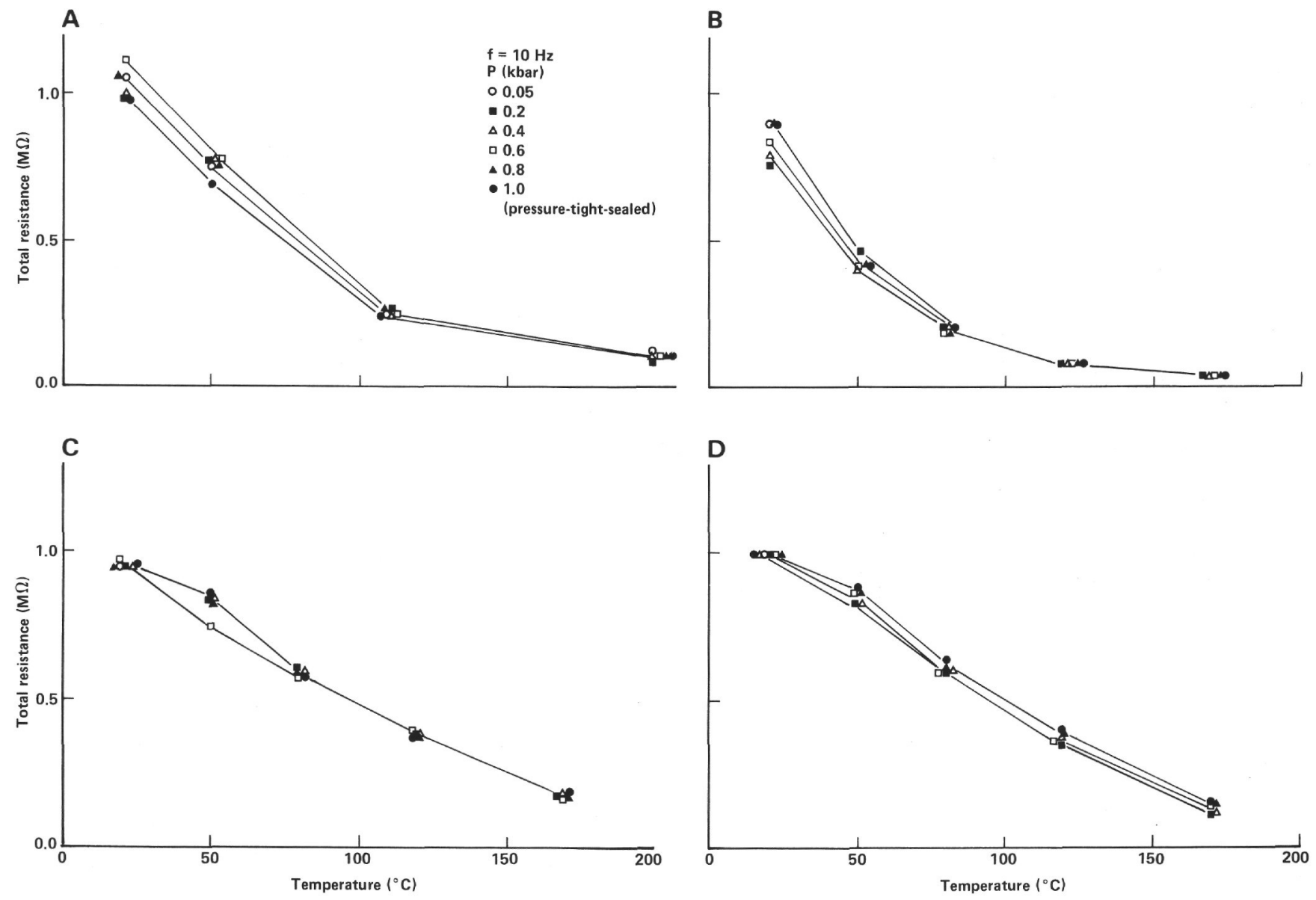

Figure 8. Change in total resistivity with respect to temperature in Hole 504B, measured under different pressures (P) with a fixed current source frequency, of $10 \mathrm{~Hz}$. A. Section 73-1. B. Section 83-1. C. Section 116-1. D. Section 136-1. 


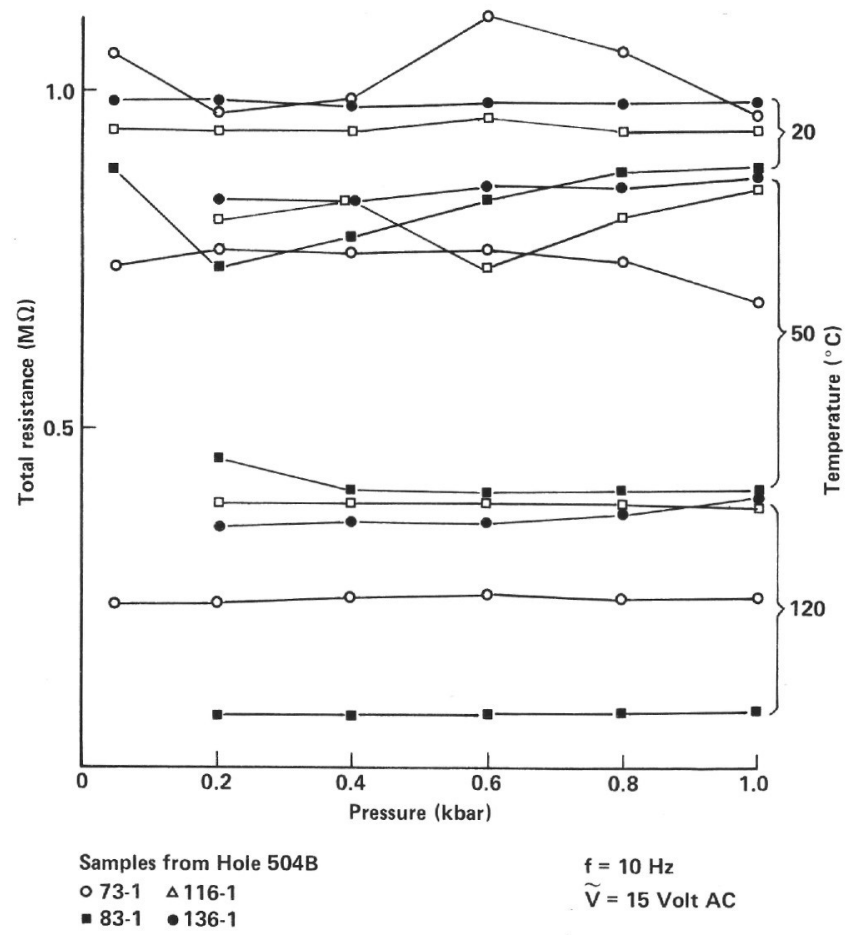

Figure 9. Decay of resistivity caused by temperature increase, influence of pressure is scarcely observed.
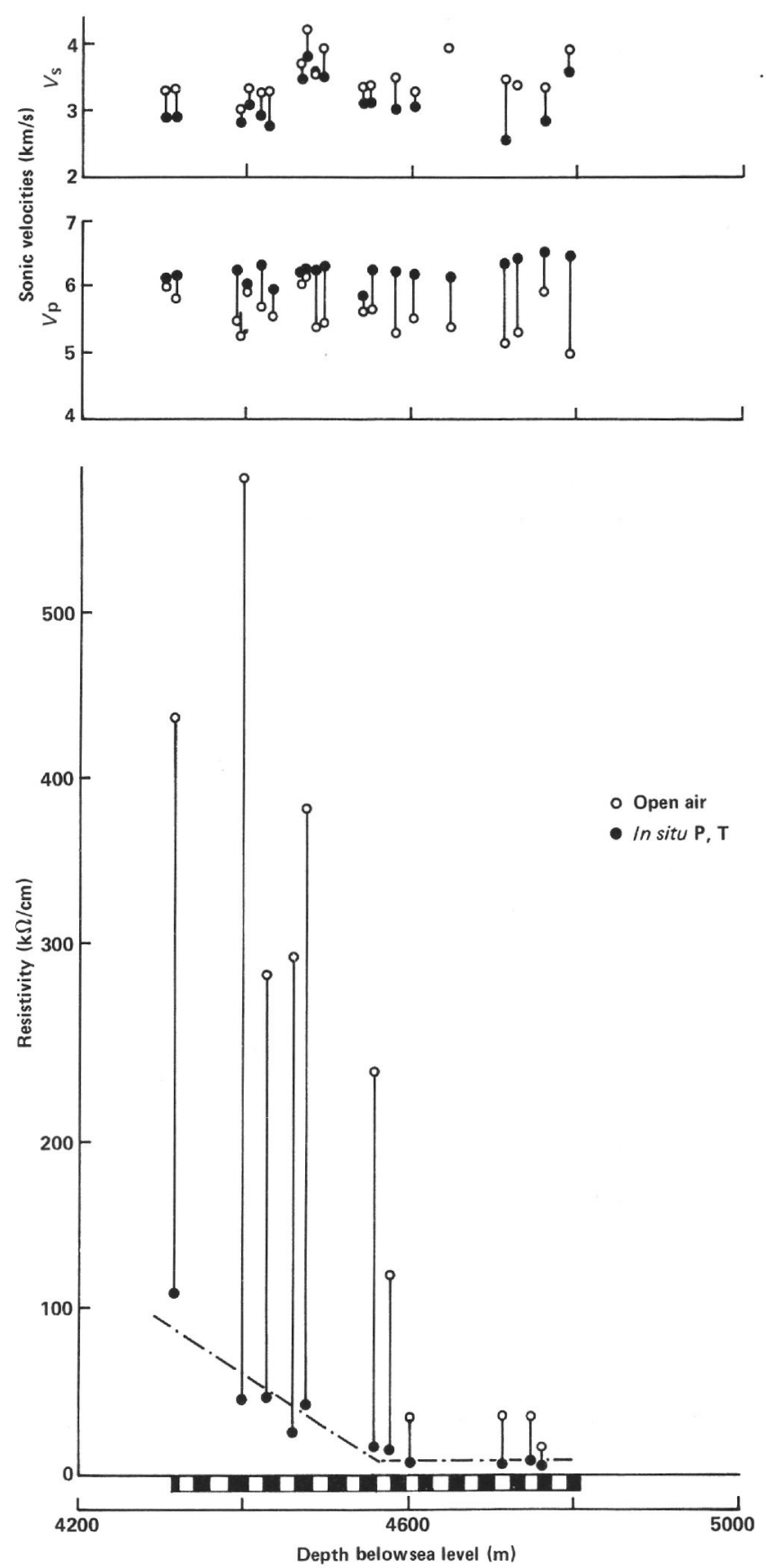

Figure 10. Comparison of $V_{\mathrm{p}}, V_{\mathrm{s}}$, and $R$ under atmospheric pressure and room temperature with values obtained under in situ conditions, Hole 504B, Leg 83. Horizontal bar represents the interval of Hole 504B drilled during Leg 83 . 